\title{
El desgarrador canto a la muerte. Análisis filosófico de la obra de Federico García Lorca
}

\author{
The heartbreaking song to Death. Philosophical \\ Analysis of the work of Federico García Lorca
}

\author{
GLORIA LUQUE MOYA \\ Universidad de Málaga (España)
}

Recibido: 04.10.2019

Aceptado: 04.12.2019

\section{RESUMEN}

La muerte es un asunto central en la obra de Federico García Lorca, que llego a convertirse en una obsesión que impregnó su bibliografía al completo. Este tema, común entre otros poetas y escritores de la época, adquiere un tamiz especial de la mano del literato que afronta y reflexiona sobre la misma a través de sus poemas y piezas teatrales. Este artículo plantea un análisis filosófico sobre la muerte en las páginas de Lorca, haciendo un recorrido por las principales obras dedicadas a este tema. Para ello, en primer lugar, se muestra la posición de Lorca ante la muerte y su forma de tratarla. Después, se analizará la visión de la muerte en sus poemas y piezas teatrales. A modo de conclusión, me gustaría destacar cómo la obra del poeta no considera la muerte desde una perspectiva trágica de la vida sino desde una filosofía de la creación.

PALABRAS CLAVE

\section{DUENDE; FUERZA; CREATIVIDAD}

\section{ABSTRACT}

The death is a key aspect in Federico García Lorca's work, which became an obsession imbuing his whole bibliography. This subject, common in poets and writers from the same era, achieves a special quality by the hand of the literati who faces and thinks about it through his poems and plays. This article proposes a philosophical analysis about the death in Lorca's pages doing a tour of his main works dedicated to this topic. For that, firstly, it shows Lorca's view of the death and his way of understanding. Then, it analyzes the tragic view of death in his poems and works. To conclude, I would like to highlight that the poet's 
work does not consider death from a tragic view of life but from a philosophy of creation.

\section{KEYWORDS \\ DUENDE; FORCE; CREATIVITY \\ I. INTRODUCCIÓN}

Federico García Lorca fue un poeta, dramaturgo y escritor de la generación del veintisiete, conocido por su habilidad y destreza en el uso de las palabras. Pese a que murió a la edad de treinta y ocho años se consolidó como uno de las figuras literarias más importantes del siglo XX en el ámbito español. Su obra se caracteriza por el ímpetu y la pasión propia de aquel que posee el duende, esa fuerza creativa desgarradora que penetra en las entrañas de las personas, seduciéndonos, adentrándonos a través del discurrir de la palabra en los misterios que acongojan al hombre.

Como ha puesto de relieve Betty Rita Gómez ${ }^{1}$, la inquietud de García Lorca por sondear y penetrar los rincones mis íntimos del ser humano nace de un apasionado amor a la vida y de un deseo ardiente de exponer a la muerte, la fatalidad innata e inevitable de todo lo viviente. El universo lorquiano está caracterizado por esa reflexión sobre el tiempo que pasa y la muerte que nos acecha de manera segura e implacable y que, lejos de quedarse en un discurso meramente trágico, ofrece al ser humano el impulso más profundo de desplegar su potencial creativo.

En este sentido, estas páginas se centran en el estudio de la muerte en el arte lorquiano, atendiendo especialmente al tratamiento de la misma desde la noción de duende. Para ello, en primer lugar se expondrá la propuesta de Lorca sobre la muerte a través de su noción de duende. En segundo lugar, se rastreará dicha reflexión a lo largo de sus obras, evidenciando cómo ésta no es vivida desde el fatalismo, sino como una fuerza creativa que atraviesa al ser humano. A modo de conclusión, se apuntará como la visión lorquiana de la muerte no hay que entenderla desde el pesimismo, sino que ella despierta en el ser humano el pulso más íntimo de creación, un instinto ardiente que se despliega de manera apasionada en su obra.

II. LA AFLICCIÓN DE LA MUERTE COMO FUERZA CREATIVA:

UNA APROXIMACIÓN A LA NOCIÓN DE «DUENDE»

En el año 1933, en la Sociedad de Amigos del Arte de Buenos Aires, Fe-

1 Gómez Lance, B. R., «Muerte y vida e el drama de Federico García Lorca», Hispania, Vol. 43, No. 3 (Sep., 1960), p. 376. 
derico García Lorca presentaba una comunicación sobre «el espíritu oculto de la dolorida España» ${ }^{2}$. En dicha presentación, Lorca toma la noción de «duende» del folclore y del flamenco y la transforma en una categoría estética que nos desvela la visión de la muerte del pueblo español. Allí, el poeta describe el «duende» no tanto como una cuestión de habilidad, sino como un estilo verdaderamente vivo. Esto es, en contraste con los intelectuales de la época, describe esta noción como una fuerza creativa que surge de ese sentimiento desgarrador que produce la muerte. Ahora bien, ¿cómo podemos entender ésta? Para responder a la misma tendremos que referiros a su propia biografía.

Federico García Lorca es ese tipo de escritor que solemos denominar genio. Fue un poeta y director de teatro que nos ofrece a lo largo de sus obras una reflexión sobre la muerte que parte de su experiencia vital y de su propia cultura. Él nació en 1898 en Fuente Vaqueros, un pueblo de Granada, por el que siempre sintió una fuerte afinidad. Estudió derecho, literatura y composición, aunque desde su adolescencia desplegó una particular afinidad por el teatro y la música que no se restringía a la música clásica, sino que desarrolló una afición especial por aquella procedente del folclore.

Es por este interés por lo que el poeta se sintió pronto íntimamente ligado a su amigo y compositor Manuel de Falla, con el que compartió su amor por la música, el teatro y el cante jondo. En 1922, los amigos organizan un Concurso de Cante Jondo en Granada los días trece y catorce de junio para celebrar el arte del flamenco, que incluía la música, la canción y el baile. Los principales objetivos del concurso fueron: ganar respeto para este tipo de arte; preservar este estilo de la adulteración; recompensar los cantantes que no eran profesionales y mostrar su influencia.

Lo más interesante para estas páginas de dicho concurso es la conferencia que pronuncia Lorca el diecinueve de febrero de 1922, titulada «Cante jondo. Importancia histórica y artística del canto primitivo andaluz llamado 'Cante jondo'». Esta presentación, que tenía una intención claramente educativa, nos revela mucho sobre su propia reflexión acerca del duende y de la muerte.

Lorca inicia el texto enfatizando cómo este concurso tenía la intención de presentar una nueva compresión de esta música tradicional. En ella tra-

2 García Lorca, F., Juego y teoría del duende. Barcelona: Nortesur, 2010, p. 12. 
ta de diferenciar el cante jondo, con un origen más antiguo en los sistemas musicales primitivos de la India, del flamenco que derivaría de éste y se constituiría en el siglo dieciocho. En palabras del autor:

«Se da el nombre de cante jondo a un grupo de canciones andaluzas, cuyo tipo genuino y perfecto es la siguiriya gitana, de las que derivan otras canciones aún conservadas por el pueblo como los polos, martinetes, carceleras y soleares. Las coplas llamadas malagueñas, granadinas, rondeñas, peteneras, etc., no pueden considerarse más que como consecuencia de las antes citadas, y tanto por su arquitectura como por su ritmo difieren de las otras. Estas son las llamadas flamencas». ${ }^{3}$

El cante jondo emerge de nuestro contexto natural «son un árbol más en el paisaje, una fuente más en la alameda» ${ }^{4}$. Se trata de un canto primitivo que expresa las más profundas gradaciones de dolor y pena. «Es el grito de las generaciones muertas, la aguda elegía de los siglos desaparecidos, es la patética evocación del amor bajo otras lunas y otros vientos». ${ }^{5}$ Este tipo de música captura, pues, la rara complejidad de nuestros momentos más intensos como seres humanos, aquellos que aluden al sentimiento profundo que nos aflige la muerte. Se trata de un canto que nos desvela esas sombras terribles que nos golpean y nos sacuden, aquellas que nos conmueven y nos recuerdan el constante acechar de la muerte.

«Vean ustedes, señores, la trascendencia que tiene el cante jondo y qué acierto tan grande el que tuvo nuestro pueblo al llamarlo así Es hondo, verdaderamente hondo, más que todos los pozos y todos los mares que rodean el mundo, mucho más hondo que el corazón actual que lo crea y la voz que lo canta, porque es casi infinito. Viene de razas lejanas, atravesando el cementerio de los años y las frondas de los vientos marchitos. Viene del primer llanto y el primer beso». ${ }^{6}$

En este sentido, el duende será esa fuerza creativa que surge cuando nos vemos cara a cara con la muerte. El esfuerzo difícil que supone superar este inevitable destino, no conlleva un mero padecer y aceptar pasivo, sino que genera un proceso creativo significativo. El duende será esa desgarradora vía desde la que afrontar la muerte que el folclore andaluz nos desvela. Lorca cuenta una historia sobre Pastora Pavon, conocida como La Niña de los Peines ${ }^{7}$. Una vez ella estaba cantando en una pequeña taberna

3 García Lorca, F., Poema del cante jondo. Seguido de tres textos teóricos de Federico García Lorcay Manuel de Falla. Madrid: Alianza, 1994, p. 147.

4 IIbidem, p. 160.

5 Ibidem, p. 149.

6 Ibidem., p. 156.

7 Este nombre provenía de unos tangos que solía cantar y que nunca llegó a grabar que 
en Cádiz, donde había especialistas en flamenco. «Jugaba con su voz de sombra, con su voz de estaño fundido, con su voz cubierta de musgos; y se la enredaba en la cabellera o la mojaba en manzanilla o la perdía en unos jarales oscuros y lejanísimos.» ${ }^{8} \mathrm{La}$ audiencia no hizo nada, sólo guardo silencio. Entonces La Niña se levantó como una loca, se bebió un gran trago y comenzó a cantar sin voz, sin aliento, con duende:

«La Niña de Los Peines tuvo que desgarrar su voz porque sabía que la estaba oyendo gente exquisita que no pedía formas sino tuétano de formas, música pura con el cuerpo sucinto para poder mantenerse en el aire. Se tuvo que empobrecer de facultades y de seguridades; es decir, tuvo que alejar a su musa y quedarse desamparada, que su duende viniera y se dignara luchar a brazo partido. ¡Y cómo cantó! Su voz ya no jugaba, su voz era un chorro de sangre, digna, por su dolor y su sinceridad, de abrirse como una mano de diez dedos por los pies clavados, pero llenos de borrasca, de un Cristo de Juan de Junis.

La audiencia no se pudo contener más y la emoción del duende emergió en sus cuerpos, ya que cuando el duende escapa todos pueden sentirlo. Ese sobrecogedor canto que nos conmueve y nos sitúa en un cara a cara con la muerte. Al igual que la Niña de los Peines, Lorca no sólo realiza una teoría estética del duende, sino que introduce el duende en sus propias obras, ofreciendo una visión de la muerte imponente, que nos enfrenta con el vacío que viene después:

$$
\begin{gathered}
\text { «Los laberintos } \\
\text { que crea el tiempo, } \\
\text { se desvanecen. } \\
\text { (Sólo queda } \\
\text { el desierto). } \\
\text { El corazón, } \\
\text { fuente del deseo, } \\
\text { se desvanece. } \\
\text { (Sólo queda } \\
\text { el desierto). } \\
\text { La ilusión se la aurora } \\
\text { Y los besos, } \\
\text { Se desvanecen. } \\
\text { Sólo queda } \\
\text { el desierto. }
\end{gathered}
$$

decían: «Péinate tú con mis peines, que mis peines son de azúcar, quien con mis peines se peina, hasta los dedos se chupa. Péinate tú con mis peines, mis peines son de canela, la gachi que se peina con mis peines, canela lleva de veras».

8 Juego y teoría del duende op. cit., p. 16.

9 Ibidem, p. 18. 
Un ondulado

Desierto». ${ }^{10}$

Para Lorca, las coplas populares, ya vengan del corazón de la sierra, del naranjal sevillano o de las armoniosas costas mediterráneas, todas tienen un fondo común: el Amor y la Muerte..., pero un Amor y una Muerte vistos a través de la Sibyla, ese personaje tan oriental, verdadera esfinge de Andalucía. ${ }^{11}$ En el fondo de todos los poemas late la pregunta, la terrible pregunta que no tiene contestación. Esto será lo que también marcará el ritmo de su obra: ese hondo problema emocional, la Muerte, que es la pregunta de las preguntas. En otras palabras, en el verso lorquiano encontramos esa angustia hacia la muerte en el que podemos rastrear su propia visión y su reflexión sobre la misma. Esto es lo que se tratará de evidenciar en la siguiente sección, a través de un recorrido por algunas de sus principales obras.

\section{LA VISIÓN DE LA MUERTE EN EL UNIVERSO LORQUIANO}

Diversos especialistas en la obra de Lorca han puesto de manifiesto cómo para abordar los temas centrales el autor emplea frecuentemente símbolos. Pero quizás de entre todos los aspectos a tratar el que más destaca es el de la muerte. Esta obsesión vital que puede rastrearse a través de los distintos elementos será simbolizada a través de una gran variedad de elementos, tales como la luna, el arco, la cal, el agua estancada, la sangre derramada, las hierbas, los metales, etc. El uso de dichos símbolos, junto con el empleo de figuras literarias tradicionales como la metáfora o la prosopopeya, caracterizaran desde sus inicios una obra eminentemente expresiva.

Ya en sus primeras obras podemos rastrear estos recursos, a través de las canciones y romances que el autor escribe para transmitirnos sobre el tiempo y la muerte. Estos se enmarcan en ambientes muy caracterizados por la luz de la noche y del alba en las ciudades andaluzas. El recurso de la luminosidad lo encontramos ya en el «Poema del cante jondo» (1921), en el que Lorca recurrirá a los faroles, velas y candiles para representar a la muerte. Como ha puesto de relieve Javier Salazar ${ }^{12}$, con su luz amortigua-

10 Poema del cante jondo op. cit., pp. 66-67.

11 Ibidem, p. 157.

12 Salazar Rincón, J., «Cirios, candiles, velones... símbolos de angustia y muerte en la obra 
da y balbuciente, son símbolos de la pena que desprenden las saetas, las siguiriyas o las peteneras, cuyas coplas, acompañadas por gritos desgarrados, trazan sobre el aire extraños signos de dolor y muerte. Así leemos en «Candil» de «Seis caprichos»:

$$
\begin{aligned}
& \text { «Oh, qué grave medita } \\
& \text { la llama del candil! } \\
& \text { Como un faquir indio } \\
& \text { mira su entraña de oro } \\
& \text { y se eclipsa soñando } \\
& \text { atmósferas sin viento. } \\
& \text { Cigüeña incandescente } \\
& \text { pica desde su nido } \\
& \text { a las sombras macizas, } \\
& \text { y se asoma temblando } \\
& \text { a los ojos redondos } \\
& \text { del gitanillo muerto». }
\end{aligned}
$$

En Primeras canciones (1922) y Canciones (1927) transmite desde ese ardor juvenil propio de un excelente poeta retratos de su infancia apasionada en las tierras andaluzas. Así leemos en el poema «Los encuentros de un caracol aventurero»:

«Vengo de mi casa y quiero

Volverme muy pronto a ella.

Es un bicho muy cobarde,

Exclama la rana ciega,

¿No cantas nunca? No canto,

Dice el caracol. ¿Ni rezas?

Tampoco: nunca aprendí.

¿Ni crees en la vida eterna?

¿Qué es eso?

Pues vivir siempre

En el agua más serena,

Junto a una tierra florida

Que a un rico manjar sustenta.

Cuando niño a mí me dijo,

Un día, mi pobre abuela

Que al morirme yo e iría

Sobre las hojas más tiernas

De los árboles más altos». ${ }^{14}$

de Federico García Lorca, Epos XV (1999), p. 203.

13 Poema del cante jondo op. cit., p. 120.

14 García Lorca, F., Libro de poemas. Primeras canciones. Canciones. Seis poemas gallegos. Buenos 
En este poema se aprecian algunos de los elementos principales que Lorca utiliza para simbolizar la muerte (el agua serena frente a la estancada, la hierba, etc.), pero sobretodo cómo la cuestión de la muerte será una obsesión central desde sus inicios. Un poco más adelante, en la «Canción otoñal», Lorca se pregunta « $i Y$ si la muerte es la muerte que será de los poetas y de las cosas dormidas que ya nadie las recuerda?»». ${ }^{15}$ Esta angustia por el sentir del tiempo, por la premura con la que se van agotando nuestros días, con la congoja que conlleva pensar en el final, en la nada, se palpa por toda la obra. De este modo, en la canción «Lluvia» leemos:

$$
\begin{aligned}
& \text { «Es la aurora del fruto. La que nos trae las flores } \\
& \text { Y nos unge de espíritu santo de los mares. } \\
& \text { La que derrama vida sobre las sementeras } \\
& \text { Y en el alma la tristeza de lo que no se sabe. } \\
& \text { La nostalgia terrible de una vida perdida, } \\
& \text { El fatal sentimiento de haber nacido tarde, } \\
& \text { O la ilusión inquieta de una mañana imposible } \\
& \text { Con la inquietud cercana del dolor de la carne». }{ }^{16}
\end{aligned}
$$

En julio de 1928 Lorca publica su tercer libro poético, el Romancero gitano. Con esta obra el poeta pretende dar voz a un grupo de población menospreciado, pero sobretodo, como ha señalado Mario Hernández ${ }^{17}$, hay que encuadrarla como una obra que se desprende del Poema del cante jondo. En ella aborda la muerte y el choque del mundo gitano con la sociedad a través de una poesía que tiene sus raíces en los cantos populares. Como el propio Lorca indica:

«El libro es un retablo de Andalucía con gitanos, caballos, arcángeles, planetas, con su brisa judía, con su brisa romana, con ríos, con crímenes, con la nota vulgar del contrabandista y la nota celeste de los niños desnudos de Córdoba que burlan a San Rafaels. ${ }^{18}$

Ahora bien, no hay que entenderla como una obra folclórica, sino que Lorca transmite con una maravillosa lírica las diferentes historias, hechos y romances que le van llegando. Así tenemos la «Muerte de Antonio el Camborio» en el que narra el asesinato del Camborio:

«Tres golpes de sangre tuvo

Aire: Editorial Losada, 1944, p. 21.

15 Ibidem p. 27.

16 Ibidem, p. 41.

17 García Lorca, F., Romancero gitano. Madrid: Alianza, 2002, p. 14.

18 García Lorca, F., «Conferencia-recital del Romancero gitano», en Romancero gitano op. cit., p. 150. 
y se murió de perfil.

Viva moneda que nunca se volverá a repetir.

Un ángel marchoso pone su cabeza en un cojín.

Otros de rubor cansado, encendieron un candil.

Y cuando los cuatro primos

llegan a Benamejí, voces de muerte cesaron cerca del Guadalquivir»». ${ }^{19}$

En la misma línea se muestra el «Romance de la muerte de Torrijos», en el que leemos:

$$
\begin{gathered}
\text { «Entre el ruido de las olas } \\
\text { sonó la fusilería, } \\
\text { y muerte quedó en la arena, } \\
\text { sangrando por tres heridas, } \\
\text { el valiente caballero } \\
\text { con toda su compañía. } \\
\text { La muerte, con ser la muerte, } \\
\text { no deshojó su sonrisa. } \\
\text { Sobre los barcos lloraba } \\
\text { toda la marinería, } \\
\text { y las más bellas mujeres, } \\
\text { enlutadas y afligidas } \\
\text { lo van llorando también } \\
\text { por el limonar arriba». }{ }^{20}
\end{gathered}
$$

Esta obra se caracteriza por un gran número de elementos utilizados para simbolizar la muerte. Los arcos, especialmente aquellos que forman parte de edificios en ruinas, son un buen ejemplo de ello ya que, como ha destacado Javier Salazar ${ }^{21}$, muestran el paso del tiempo y la destrucción. Este elemento recurrente tendrá un significado unívoco relacionado con la muerte y la aniquilación, como podemos leer en el romance «Muerto de amor»:

$$
\begin{aligned}
& \text { «Brisas de caña mojada } \\
& \text { y rumor de viejas voces }
\end{aligned}
$$

19 Romancero gitano op. cit., p. 80.

20 Ibidem, p. 118.

21 Salazar Rincón, J., «Arco, yeso y cal: tres símbolos de la muerte en la obra de Federico García Lorca», Epos XIV (1998), p. 284. 


$$
\begin{aligned}
& \text { resonaban por el arco } \\
& \text { roto de la medianoche». }
\end{aligned}
$$

La cal también será otro elemento clave que anuncia la muerte a los protagonistas de Lorca ${ }^{23}$. Es el caso del «El emplazado», en él una misteriosa voz anuncia al Amargo su final ineludible:

$$
\begin{aligned}
& \text { «Ya puedes cortar, si gustas, } \\
& \text { las adelfas de tu patio. } \\
& \text { Pinta una cruz en la puerta } \\
& \text { y pon tu nombre debajo, } \\
& \text { porque cicutas y ortigas } \\
& \text { nacerán en tu costado, } \\
& \text { y agujas de cal mojada } \\
& \text { te morderán los zapatos». }{ }^{24}
\end{aligned}
$$

En estos romances, al igual que el resto de poemas, podemos apreciar como hay «un personaje común» que cohesiona toda la obra: la Pena. No obstante, ésta no hay que asociarla a la melancolía, la nostalgia, o ninguna otra aflicción o dolencia del ánimo; sino que viene dada por la acechante pregunta que no haya respuesta: la muerte. Así dirá Lorca: «La Pena, que se filtra en el tuétano de los huesos y la savia [...]; que es un sentimiento más celeste que terrestre; pena andaluza que es una lucha de la inteligencia amorosa con el misterio que la rodea y no puede comprender. ${ }^{25}$

En este sentido, el poema que mejor muestra esta visión trágica es el «Romance de la pena negra», en el que Lorca nos expone a Soledad Montoya acongojada por la pena producida por ese ansia sin objeto, por ese «amor agudo a nada con una seguridad de que la muerte (preocupación perenne de Andalucía) está respirando detrás de la puerta» ${ }^{26}$ :

$$
\begin{aligned}
& \text { «-¡Soledad, qué pena tienes! } \\
& \text { ¡Qué pena tan lastimosa! } \\
& \text { Lloras zumo de limón } \\
& \text { agrio de espera y de boca. } \\
& \text { ¡QQué pena tan grande! Corro } \\
& \text { mi casa como una loca, } \\
& \text { mis dos trenzas por el suelo } \\
& \text { de la cocina a la alcoba. }
\end{aligned}
$$

22 Romancero gitano op. cit., p. 81.

23 «Arco, yeso y cal» op. cit., p. 290

24 Romancero gitano op. cit., p. 85.

25 «Conferencia-recital del Romancero gitano» op. cit., pp. 150-151.

26 Ibidem, pp. 155-156. 


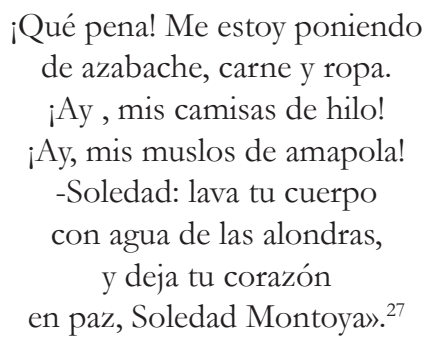

Este personaje común también será el que permeará sus obras teatrales: Bodas de sangre (1933), Yerma (1934) y La casa de Bernarda Alba (1936). Aunque quizás este se hace más palpable en Bodas de sangre, en la que la muerte es encarnada por la luna y la mendiga. En el acto tercero, en la escena del bosque, Lorca emplea la prosopopeya como figura retórica para dar voz a la luna en forma de leñador joven con la cara blanca:

$$
\begin{gathered}
\text { «[... ¿Quién se oculta? ¿Quién solloza } \\
\text { por la maleza del valle? } \\
\text { La luna deja un cuchillo } \\
\text { abandonado en el aire, } \\
\text { que siendo acecho de plomo } \\
\text { quiere ser dolor de sangre. } \\
{[\ldots] \text { Pues esta noche tendrán }} \\
\text { mis mejillas roja sangre, } \\
\text { y los juncos agrupados } \\
\text { en los anchos pies el aire. } \\
\text { ¡No haya sombra ni emboscada, } \\
\text { que no puedan escaparse! } \\
\text { ¡Que quiero entrar en un pecho } \\
\text { para poder calentarme! } \\
\text { ¡Un corazón para mí! } \\
\text { ¡Caliente!, que se derrame } \\
\text { por los montes de mi pecho; } \\
\text { dejadme entrar, jay dejadme! [...]». }{ }^{28}
\end{gathered}
$$

No es casual que Lorca escoja la luna, ya que esta será uno de los símbolos claves con los que Lorca introduce la muerte. Esta será un elemento recurrente ya que, como ha puesto de relieve Manuel Antonio Arango ${ }^{29}$, tiene un poder fatídico, tiene el misterio de vida y de muerte. Arango cree

27 Romancero gitano op. cit., p. 64.

28 García Lorca, F., Bodas de sangre. Madrid: Espasa Calpe, 1994, pp. 143-144.

29 Arango, M. A., Símbolo y simbología en la obra de Federico García Lorca. Madrid: Editorial Fundamentos, 1995, pp. 58-59. 
que incluso las fases de la luna (crecimiento, curso y desaparición) corresponden al propio proceso de la vida humana que va desde el nacimiento a la muerte; de ahí que tenga una fuerte relación con los ritos funerarios.

En cualquier caso en Bodas de sangre la luna será la muerte, pero también la ayudante de la misma. Ella será la que dejará entrar sus rayos por todas partes, interviniendo en el final trágico que espera a los hombres. «Ilumina el chaleco y aparta los botones, que después las navajas ya saben el camino» ${ }^{30}$ le dirá la mendiga. La mendiga será la que conduzca a los muchachos a su inevitable final. Ésta será el personaje que propicie y anuncie el nefasto desenlace, aquella que aviva el trágico sentir de la muerte a través de la violencia desgarradora de la obra:

«Flores rotas los ojos y sus dientes

dos puñados de nieve endurecida.

Los dos cayeron, y la novia vuelve

teñida en sangre falda y cabellera.

Cubiertos con dos mantas ellos vienen

sobre los hombros de los mozos altos.

Así fue; nada más. Era lo justo.

Sobre la flor del oro, sucia arena». ${ }^{31}$

De este modo, en Bodas de sangre la muerte acecha a los personajes, se trata de un destino imparable al que se ven abocados y marcará el inescrutable final. En cambio, en La casa de Bernarda Alba y Yerma, la muerte es el tema secundario que da pie a la obra y le proporciona cohesión. En el caso de La casa de Bernarda Alba, la obra da comienzo tras la muerte del segundo marido de Bernarda Alba y la imposición a sus cinco hijas del luto más riguroso. Por su parte, en Yerma la muerte será la opción de la protagonista para resolver el problema que tiene de no poder quedarse embarazada.

En este sentido, será en su celebrado Llanto por Ignacio Sánchez. Mejías (1935), donde volveremos a encontrar ese sentimiento acongojado que nos deja la reflexión sobre la muerte. La elegía está dividida en cuatro partes, en la que la muerte lo invade todo de manera feroz. Ésta la escribe poco después de una cogida que acabo con el torero y amigo Ignacio Sánchez Mejías (1891-1934) y algunos autores consideran que con ella Lorca culminará el conjunto de poemas dedicados a la muerte ${ }^{32}$. La obra se

30 Bodas de sangre op. cit., p. 146.

31 Ibidem, p. 165.

32 García-Posada, M., «Introducción», García Lorca, F., Llanto por Ignacio Sánchez Mejías. 
divide en cuatro partes con métricas diferentes organizadas como si fuera una sinfonía, en la que se palpa el incontenible y doloroso fin del torero.

El poeta va a cantar por la muerte de su amigo, pero en él vamos a encontrar una reflexión aún más dolorosa, aquella que deja ese sentimiento de frustración, de angustia, de nada, el no saber que habrá. La muerte se presenta como algo terrible y fatal porque escapa, no se deja atrapar por esa seguridad cristiana que apunta a la inmortalidad. Para el poeta, lo único seguro es que va a llegar, pero no el qué sucederá.

Ya en la primera parte del poema se advierte la insistencia obsesiva que ocupa la muerte con el uso repetitivo de «a las cinco de la tarde». Este recurso marcará la terrible victoria de la muerte a través de ese reiterativo recurso, con ese repetido «a las cinco en punto de la tarde». Esta hora no es en realidad la hora a la que fallece el torero. Según lo que recoge Cossío en su biografía, el torero murió a las 9 horas y 45 minutos, pero Lorca introduce esta hora porque es la hora tradicional para las corridas, y con ella anuncia la hora trágica. Por ello, acaba el poema remarcando:

«A las cinco de la tarde.

¡Ay qué terribles cinco de la tarde!

¡Eran las cinco en todos los relojes!

¡Eran las cinco en sombra de la tarde!».33

Y nada se puede hacer cuando la muerte se posa sobre la persona. Una vez que ha llegado nuestro momento de poco sirven las intervenciones e instrumental quirúrgico, que al final más que ayudar se convierten en auxiliares de la muerte. De ahí que leamos en la primera parte en una clara referencia al instrumental de la enfermería que poco pudo hacer por él:

«El viento se llevó los algodones

A las cinco de la tarde.

Y el óxido sembró cristal y níquel

A las cinco de la tarde». ${ }^{34}$

En la segunda parte, la sangre vertida del torero será el eje que cohesione y una el canto. Será ese elemento común que también encontramos en otras obras de Lorca que muestra de una manera violenta y dolorosa la muerte: «Buscaba su hermoso cuerpo y encontró su sangre abierta.» ${ }^{35}$

Madrid: Castalia, 1988, p. 66.

33 Ibidem, p. 222

34 Ibidem, p. 221.

35 Ibidem, p. 227. 
De la misma manera, en Bodas de sangre, uno de los leñadores rogaba «iNo abras el chorro de sangre! $\rangle^{36}$ Se trata de una visión que el poeta rechaza tal y como él mismo indica al clamar en repetidas ocasiones «iQue no quiero verla!» ${ }^{37}$ Sin embargo, será esta muerte trágica la que convierta, en este segundo canto, al torero en héroe de mito:

$$
\begin{aligned}
& \text { «No hubo príncipe en Sevilla } \\
& \text { que comprársele pueda, } \\
& \text { ni espada como su espada } \\
& \text { ni corazón tan de veras. } \\
& \text { Como un río de leones } \\
& \text { su maravillosa fuerza, } \\
& \text { y como un torso de mármol } \\
& \text { su dibujada prudencia. } \\
& \text { Aire de Roma andaluza } \\
& \text { le doraba la cabeza } \\
& \text { donde su risa era un nardo } \\
& \text { de sal y de inteligencia». }
\end{aligned}
$$

Y esta visión se hace más evidente en la tercera parte a través de los distintos lamentos pesimistas que ensalzan esa visión de héroe: «ya se acabó», «ya está sobre la piedra» «ya duerme sin fin», «estamos con un cuerpo presente que se esfuma ${ }^{39}$. Sin embargo, lo más interesante de esta tercera parte es cómo se hace palpable ese rechazo a la eternidad; esa eternidad que nos alivia ante el doloroso destino que supone el fin de nuestra existencia:

«Yo quiero ver aquí los hombres de voz dura.

Los que doman caballos y dominan los ríos:

Los hombres que les suena el esqueleto y cantan

Con una boca llena de sol y pedernales.

Aquí quiero yo verlos. Delante de la piedra.

Delante de este cuerpo con las riendas quebradas.

Yo quiero que me enseñen dónde está la salida

Para este capitán atado por la muerte». ${ }^{40}$

Nadie se libra del destino final, como podemos comprobar en el feroz

36 Bodas de sangre op. cit., p. 151.

37 Llanto por Ignacio Sánchez. Mejías op. cit., p. 226.

38 Ibidem, pp. 227-228.

39 Ibidem, pp. 233-234.

40 Ibidem, p. 234. 
grito que lanza al final de esta tercera parte: «iTambién se muere el mar! $»^{41}$ Esta negación a la inmortalidad cristiana se puede rastrear de forma aún más latente en la última parte, titulada «Alma ausente». Si recordamos las palabras consoladoras de Jesús, este decía «El que cree en mí, aunque esté muerto vivirá.» Lorca, en cambio, repetirá a su héroe «te has muerto para siempre»:

«No te conoce el toro ni la higuera, ni caballos ni hormigas de tu casa.

No te conoce el niño ni la tarde porque te has muerto para siempre». ${ }^{42}$

$\mathrm{Y}$ este «para siempre» adquiere un sentido de incredulidad y desconfianza en el más allá que se verá claramente reflejado unas estrofas más adelante cuando leemos:

«Porque te has muerto para siempre, como todos los muertos de la Tierra, como todos los muertos que se olvidan, en un montón de perros apagados». ${ }^{43}$

Del mismo modo, ya en el prólogo de su Libro de poemas (1921), cuando Lorca interpela directamente a dios para que hunda su cetro en el corazón también le indica:

$$
\begin{gathered}
\text { «Mas si no quieres hacerlo, } \\
\text { me da lo mismo, } \\
\text { guárdate tu cielo azul, } \\
\text { que es tan aburrido, } \\
\text { el rigodón de los astros. } \\
\text { Y tu infinito, } \\
\text { que yo pediré prestado } \\
\text { el corazón a un amigo. } \\
\text { Un corazón con arroyos } \\
\text { y pinos, } \\
\text { y un ruiseñor de hierro } \\
\text { que resista } \\
\text { el martillo } \\
\text { de los siglos». }
\end{gathered}
$$

Este poema nos muestra, por tanto, como el autor no despliega una

41 Ibidem.

42 Ibidem, p. 238.

43 Ibidem.

44 Libro de poemas. Primeras canciones op. cit., p. 103. 
perspectiva fatalista y temerosa. Su visión sobre la muerte no hay que adscribirla a un mero materialismo negro y trágico que reduce al hombre a polvo, ceniza y nada, sino que adquiere otro tamiz. Este poema muestra de una manera formidable cómo la muerte y la reflexión sobre la misma se convierte en fuerza creativa en la obra de Lorca. El poeta realiza este poema descubriéndonos sus más sinceros pensamientos y su más profundo dolor por el fallecimiento de su amigo. Él lo hace a través de palabras que se convierten en melodía y que recogen la propia muerte como una sinfonía con duende que sobrecoge al fallecido. Ya en la primera parte nos estremece cuando leemos:

$$
\begin{aligned}
& \text { «Comenzaron los sones de bordón } \\
& \text { a las cinco de la tarde. } \\
& \text { Las campanas de arsénico y el humo } \\
& \text { a las cinco de la tarde». }{ }^{45}
\end{aligned}
$$

Y más adelante continúa aludiendo a: «huesos y flautas suenan en su oído», o «trompas de lirio por las verdes ingles». ${ }^{46}$.De esta manera, incluso el lamento por la muerte se transforma en música y esperanza. No hay fatalismos ni una visión de oscuridad al final, aunque para Lorca la vida nos conduce inevitablemente a nuestro sepulcro. De este modo, ese destino final que formaba parte del sentir del pueblo andaluz y que el poeta rescata para sus obras no sé preguntará sobre el por qué. Incluso en el prólogo de su Libro de poemas, en el que Lorca interroga directamente a dios sobre este imparable destino, el autor no cuestiona sobre el fin, sino sobre la pena y la angustia:

$$
\begin{gathered}
\text { «Dime, Señor, } \\
\text { ¡Dios mío! } \\
\text { ¿Nos hundes en la sombra } \\
\text { del abismo? } \\
\text { ¿Somos pájaros ciegos } \\
\text { sin nidos? } \\
\text { La luz se va apagando. } \\
\text { ¿Y el aceite divino? } \\
\text { Las olas agonizan } \\
\text { ¿Has querido } \\
\text { jugar como si fuéramos } \\
\text { soldaditos? }
\end{gathered}
$$

45 Ibidem.

46 Ibidem. 


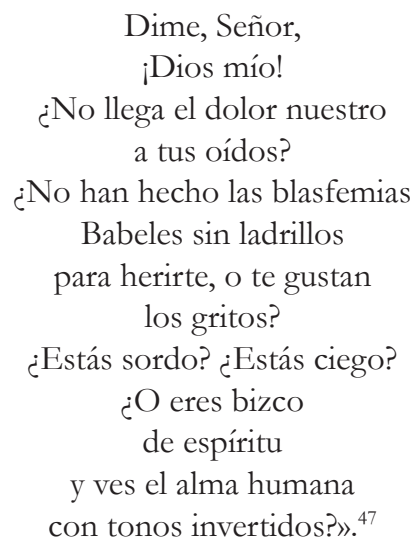

El autor no quiere saber el porqué, sino que, por el contrario, le preguntará sobre la angustia y el dolor de la persona. Y precisamente, será esa pena, esa rabia la que permita aflorar, el duende, esa fuerza de creación. Así, en el poema «Memento» de su obra Poema del cante jondo el poeta escribe que lo entierren con su guitarra:

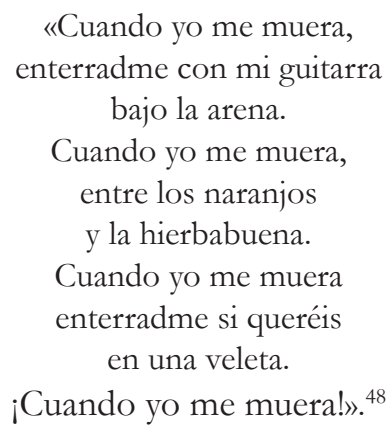

De esta manera, en esta sección se ha tratado de evidenciar cómo la muerte en el universo lorquiano aparece a través del duende, esa fuerza que nos acongoja, pero nos hace aflorar nuestro fiero impulso creador. Como ha puesto de manifiesto Lorca ${ }^{49}$, en todos los países la muerte es un fin, pero en España esto no es así, nos levantamos, corremos las cortinas y desplegamos esa dimensión estética que nos constituye y Lorca será un maestro de ello.

47 Libro de poemas. Primeras canciones op. cit., p. 103.

48 Poema del cante jondo op. cit., p. 113.

49 Juego y teoría del duende op. cit., pp. 21-22. 


\section{CONCLUSIONES}

Cualquier persona que intente adentrarse en la noción lorquiana de duende descubrirá que no existe mapa ni ejercicio que nos pueda guiar por tal empresa. Se saben los caminos para buscar a dios, dirá Lorca, pero de esa fuerza creativa llamada duende «sólo se sabe que quema la sangre como un trópico de vidrios, que agota, que rechaza toda la dulce geometría aprendida, que rompe los estilos, que se apoya en el dolor humano que no tiene consuelo.» ${ }^{50}$

Como ha puesto de manifiesto José Martínez Hernández ${ }^{51}$, en su obra Lorca nos muestra un sujeto pasional, agónico y doliente, antes individuo sentimental que racional. Ahora bien, en contra de lo que indica el autor, esto no ha de entenderse como una filosofía trágica, todo lo contrario, esa reflexión desgarradora nos introduce desde el concepto de duende una filosofía de la creación, que alude al potencial humano para sobreponerse a su inevitable destino a través de una fuerza creativa.

A lo largo de estas páginas se ha tratado de evidenciar lo que Rupert Allen denomina la compresión simbólica de la vida lorquiana ${ }^{52}$, una visión que no trata de hallar consuelo en la eternidad, sino que se mofa de ese «aburrido cielo azul». Lorca no quiere alcanzar la inmortalidad, sino que busca esos lugares en los que el duende aparece, los bordes de la herida, el cuerpo desgarrado, aquellos sitios «donde las formas se funden en un anhelo superior a sus expresiones visibles». El poeta nos enseña así a través de su obra de ese impulso por el que los españoles, y en particular el pueblo andaluz, interpretan la muerte no desde el silencio (como hará la musa) o desde las lágrimas (como hará el ángel), sino desde la creatividad del hombre.

REFERENCIAS BIBLIOGRÁFICAS:

Allen, R. C., The Symbolic World of Federico Garcia Lorca. Albuquerque: University of New Mexico, 1972.

50 Ibidem, p. 15.

51 Martínez Hernández, J., «La teoría estética de Federico García Lorca», en Alcaraz-. Carrasco-Rubio (eds.), Art, Emotion and Value. 5th Mediterranean Congress of Aesthetics, 2011, p. 94. Disponible en https://www.um.es/vmca/proceedings/docs/VMCA-Proceedings. pdf.

52 Allen, R. C., The Symbolic World of Federico García Lorca. Albuquerque: University of New Mexico, 1972, p. 7. 
Arango, M. A., Simbolo y simbología en la obra de Federico García Lorca. Madrid: Editorial Fundamentos, 1995.

García Lorca, F., Bodas de sangre. Madrid: Espasa Calpe, 1994.

García Lorca, F., Juego y teoría del duende. Barcelona: Nortesur, 2010.

García Lorca, F., La casa de Bernarda Alba. Madrid: Cátedra, 2005.

García Lorca, F., Libro de poemas. Primeras canciones. Canciones. Seis poemas gallegos. Buenos Aire: Editorial Losada, 1944.

García Lorca, F., Llanto por Ignacio Sánchez Mejías. Madrid: Castalia, 1988.

García Lorca, F., Poema del cante jondo. Seguido de tres textos teóricos de Federico García Lorca y Manuel de Falla. Madrid: Alianza, 1994.

García Lorca, F., Romancero gitano. Madrid: Alianza, 2002.

Gómez Lance, B. R., «Muerte y vida en el drama de Federico García Lorca», Hispania, Vol. 43, No. 3 (Sep., 1960), pp. 376-377.

Martínez Hernández, J., «La teoría estética de Federico García Lorca», en $\mathrm{M}^{\mathrm{a}} \mathrm{J}$. Alcaraz, M. Carrasco y S. Rubio (eds.), Art, Emotion and Value. 5th Mediterranean Congress of Aesthetics, 2011, pp. 91-100. Disponible en https://www.um.es/vmca/proceedings/docs/VMCA-Proceedings.pdf.

Salazar Rincón, J., «Arco, yeso y cal: tres símbolos de la muerte en la obra de Federico García Lorca», Epos XIV (1998), pp. 277-292.

Salazar Rincón, J., «Cirios, candiles, velones... símbolos de angustia y muerte en la obra de Federico García Lorca, Epos XV (1999), pp. 199-212.

GLORIa LuQue MoYa es Investigadora posdoctoral en Filosofía por la Universidad de Málaga.

\section{Lineas de investigación:}

John Dewey, Filosofía Comparada, Estética de lo cotidiano.

Publicaciones recientes:

- El pulso estético de la vida cotidiana, Granada: Comares, 2019.

- «En torno a la creación. Un diálogo entre Hegel y John Dewey», Cuadernos Salmantinos de Filosofía, 46, 2019, pp. 255-271.

- «La noción de criatura viva en el naturalismo cultural de John Dewey», Estudios de Filosofía, 59, Enero-Junio, Universidad de Antioquia, 2019, pp. 121-138.

Dirección electrónica: glorialm@uma.es 
